\title{
Communication \\ Effects of Annealing Atmosphere on Electrical Performance and Stability of High-Mobility Indium-Gallium-Tin Oxide Thin-Film Transistors
}

\author{
Hwan-Seok Jeong, Hyun Seok Cha, Seong Hyun Hwang and Hyuck-In Kwon* \\ School of Electrical and Electronics Engineering, Chung-Ang University, Seoul 06972, Korea; \\ hwanseok518@naver.com (H.-S.J.); ckgustjr0803@naver.com (H.S.C.); ajttjdwlsgus@naver.com (S.H.H.) \\ * Correspondence: hyuckin@cau.ac.kr
}

Received: 11 October 2020; Accepted: 6 November 2020; Published: 7 November 2020

\begin{abstract}
In this study, we examined the effects of the annealing atmosphere on the electrical performance and stability of high-mobility indium-gallium-tin oxide (IGTO) thin-film transistors (TFTs). The annealing process was performed at a temperature of $180^{\circ} \mathrm{C}$ under $\mathrm{N}_{2}, \mathrm{O}_{2}$, or air atmosphere after the deposition of IGTO thin films by direct current magnetron sputtering. The field-effect mobility $\left(\mu_{\mathrm{FE}}\right)$ of the $\mathrm{N}_{2}$ - and $\mathrm{O}_{2}$-annealed IGTO TFTs was $26.6 \mathrm{~cm}^{2} / \mathrm{V} \cdot \mathrm{s}$ and $25.0 \mathrm{~cm}^{2} / \mathrm{V} \cdot \mathrm{s}$, respectively; these values were higher than that of the air-annealed IGTO TFT $\left(\mu_{\mathrm{FE}}=23.5 \mathrm{~cm}^{2} / \mathrm{V} \cdot \mathrm{s}\right)$. Furthermore, the stability of the $\mathrm{N}_{2-}$ and $\mathrm{O}_{2}$-annealed IGTO TFTs under the application of a positive bias stress (PBS) was greater than that of the air-annealed device. However, the $\mathrm{N}_{2}$-annealed IGTO TFT exhibited a larger threshold voltage shift under negative bias illumination stress (NBIS) compared with the $\mathrm{O}_{2}$ - and air-annealed IGTO TFTs. The obtained results indicate that $\mathrm{O}_{2}$ gas is the most suitable environment for the heat treatment of IGTO TFTs to maximize their electrical properties and stability. The low electrical stability of the air-annealed IGTO TFT under PBS and the $\mathrm{N}_{2}$-annealed IGTO TFT under NBIS are primarily attributed to the high density of hydroxyl groups and oxygen vacancies in the channel layers, respectively.
\end{abstract}

Keywords: indium-gallium-tin oxide; thin-film transistor; annealing atmosphere; field-effect mobility; electrical stability

\section{Introduction}

Since the inceptive report on indium-gallium-zinc oxide (IGZO) thin-film transistors (TFTs) published by Nomura et al. in 2004, IGZO TFTs have attracted significant research interest, owing to their excellent electrical properties, high uniformity, and low fabrication costs. IGZO TFTs are widely used as the backplanes of large-area flat-panel displays, including active matrix organic light-emitting diode (OLED) displays [1-5]. However, the field-effect mobility $\left(\mu_{\mathrm{FE}}\right)$ of IGZO TFTs is approximately $10 \mathrm{~cm}^{2} / \mathrm{V} \cdot \mathrm{s}$, which is insufficient to meet the requirements of ultra-high-resolution and high-frame-rate next-generation displays. Over the past decade, various oxide TFTs with higher field-effect mobilities than those of IGZO TFTs have been extensively studied for next-generation display applications. Among these transistors, indium-gallium-tin oxide (IGTO) TFTs are promising as high-mobility oxide TFTs because of their excellent performance, even under low-temperature annealing conditions $\left(<200^{\circ} \mathrm{C}\right)$. The IGTO alloy comprises $\mathrm{Sn}$ cations instead of the $\mathrm{Zn}$ cations in IGZO, where the similar electronic configuration of the $\mathrm{Sn}^{4+}$ and $\mathrm{In}^{3+}$ ions enhances the formation of percolation conduction paths and increases the electron mobility of the former [6-8].

The oxygen-related species present in oxide thin-film transistors (TFTs), such as oxygen vacancies $\left(V_{\mathrm{O}}\right)$ or hydroxyl $(\mathrm{OH})$ groups, have a significant impact on the stability and electrical characteristics 
of the TFTs $[9,10]$. Thus far, extensive studies have been conducted to investigate the effects of various process conditions on the concentration of oxygen-related species in the oxide channel layer [11-17]. The post-deposition annealing atmosphere has a particularly strong influence on the number of oxygen species within the channel layer and also affects the electrical properties and stability of oxide TFTs with various channel materials [18-24]. However, in most prior studies, the results obtained under various heat-treatment environments differed depending on the selected channel material and process conditions, suggesting the need to determine the most suitable annealing atmosphere for IGTO TFTs in order to enhance the electrical characteristics of the IGTO TFTs. However, to date, the influence of the annealing environment on the electrical properties of IGTO TFTs has not been examined. In this study, we investigate the effects of various annealing environments on the electrical performance and stability of IGTO TFTs. For this purpose, post-deposition annealing is performed at a temperature of $180{ }^{\circ} \mathrm{C}$ under $\mathrm{N}_{2}, \mathrm{O}_{2}$, and air atmosphere. From the obtained results, it is concluded that $\mathrm{O}_{2}$ gas is the most suitable post-deposition atmosphere for IGTO TFT fabrication.

\section{Experimental}

Experiments were conducted using bottom-gate top-source/drain electrode IGTOTFTs, where $\mathrm{p}^{+}-\mathrm{Si}$ wafers served as both the substrates and gate electrodes. A $100 \mathrm{~nm}$ thick $\mathrm{SiO}_{2}$ layer was thermally grown on top of a $\mathrm{Si}$ wafer as the gate insulator, and a $20 \mathrm{~nm}$ thick IGTO thin film was deposited on top of a $\mathrm{SiO}_{2} / \mathrm{p}^{+}$-Si substrate via direct current (DC) magnetron sputtering of a 3-inch IGTO target. Sputtering was performed using a DC power of $150 \mathrm{~W}$, an $\mathrm{Ar} / \mathrm{O}_{2}$ ratio of 35/15 (sccm/sccm), and a deposition pressure of 3 mTorr; the substrate was at room temperature (RT). The source and drain electrodes were produced from a DC magnetron-sputtered $100 \mathrm{~nm}$ thick indium tin oxide layer. The channel and source/drain electrode layers were patterned using photolithography and lift-off techniques. Finally, the IGTO TFTs were thermally annealed at a temperature of $180{ }^{\circ} \mathrm{C}$ and a pressure of $1 \mathrm{~atm}$ for $2 \mathrm{~h}$ under $\mathrm{N}_{2}, \mathrm{O}_{2}$, and air atmosphere.

Figure 1 shows a schematic of the fabricated IGTO TFTs. All TFTs designed in this work had a channel width/length $(W / L)$ of $75 / 100(\mu \mathrm{m} / \mu \mathrm{m})$. The effects of post-deposition annealing on the optical, structural, and chemical properties of the fabricated IGTO thin films were investigated by ultraviolet visible-near infrared (UV-vis-NIR) spectroscopy (V-670, JASCO, Tokyo, Japan), X-ray diffraction (XRD, D8-Advance, Bruker-AXS, Wisconsin, USA) and X-ray photoelectron spectroscopy (XPS, K-alpha+, Thermo Fisher Scientific-KR, Seoul, Korea). Electrical characterization of the produced TFTs was conducted using a semiconductor parameter analyzer (4156C, Agilent Technologies, Santa Clara, USA) at RT, in the dark, under vacuum to avoid possible effects of the ambient environment on the properties of the IGTO TFT.

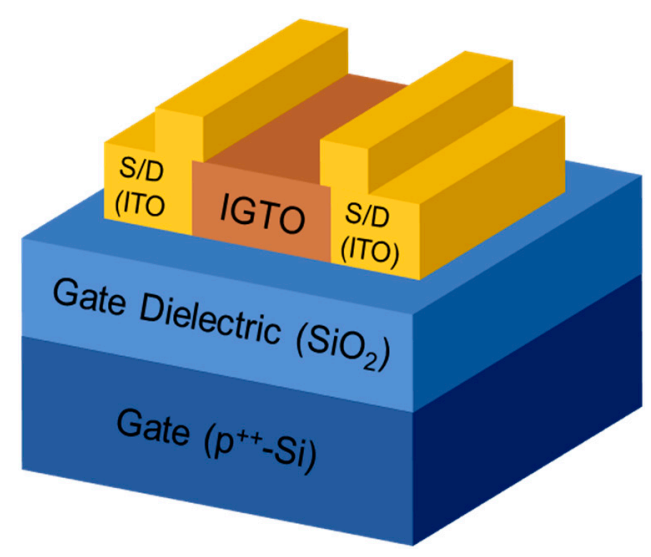

Figure 1. Cross-sectional schematic diagram of the fabricated indium-gallium-tin oxide (IGTO) thin-film transistors (TFTs). 


\section{Results and Discussion}

Figure 2 shows the transfer characteristics of the $\mathrm{N}_{2^{-}}, \mathrm{O}_{2^{-}}$, and air-annealed IGTO TFTs plotted on a semi-logarithmic scale, where $I_{\mathrm{D}}, V_{\mathrm{GS}}$, and $V_{\mathrm{DS}}$ are the drain current, gate-to-source voltage, and drain-to-source voltage, respectively. Measurements were conducted by sweeping $V_{\mathrm{GS}}$ from -30 to $30 \mathrm{~V}$ at $V_{\mathrm{DS}}=0.5 \mathrm{~V}$ for all TFTs. Table 1 lists the electrical parameters of the three fabricated TFTs. The field-effect mobility $\left(\mu_{\mathrm{FE}}\right)$ was calculated from the maximum transconductance at a $V_{\mathrm{DS}}$ of $0.5 \mathrm{~V}$, and the threshold voltage $\left(V_{\mathrm{TH}}\right)$ was obtained from the $V_{\mathrm{GS}}$ value, assuming that $I_{\mathrm{D}}=W / L \times 10^{-9}(\mathrm{~A})$. The subthreshold swing (SS) was determined as the $d V_{\mathrm{GS}} / d \log I_{\mathrm{D}}$ value in the range of $10^{-10}<I_{\mathrm{D}}<10^{-9} \mathrm{~A}$.

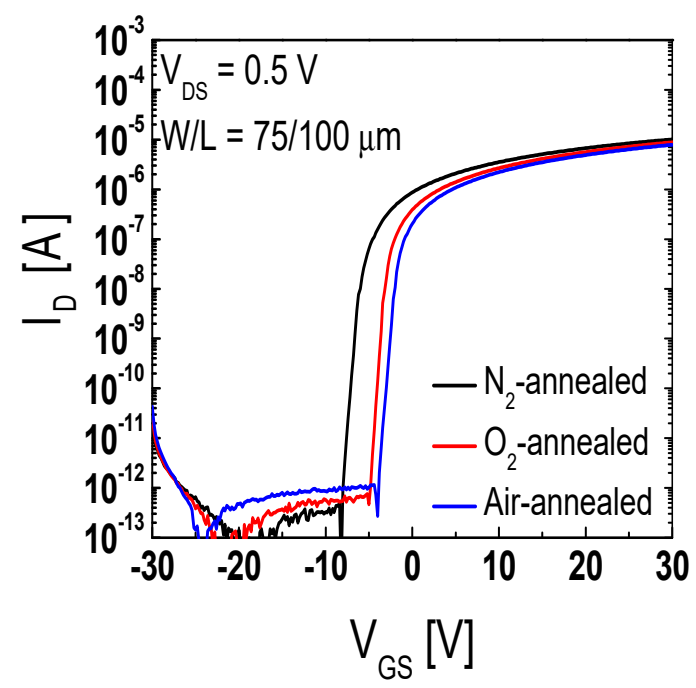

Figure 2. Transfer characteristics of $\mathrm{N}_{2^{-}}, \mathrm{O}_{2^{-}}$, and air-annealed IGTO TFTs plotted on a semi-logarithmic scale. The measurements were conducted by sweeping $V_{\mathrm{GS}}$ from -30 to $30 \mathrm{~V}$ at $V_{\mathrm{DS}}=0.5 \mathrm{~V}$ for all TFTs.

Table 1. Electrical parameters of $\mathrm{N}_{2^{-}}, \mathrm{O}_{2^{-}}$, and air-annealed IGTO TFTs.

\begin{tabular}{cccc}
\hline Annealing Atmosphere & $\mathbf{V}_{\mathbf{T H}}(\mathrm{V})$ & $\mathrm{SS}(\mathrm{V} /$ Decade $)$ & $\boldsymbol{\mu}_{\mathrm{FE}}\left(\mathrm{cm}^{\mathbf{2}} \cdot \mathbf{V}^{-\mathbf{1}} \cdot \mathbf{S}^{-\mathbf{1}}\right)$ \\
\hline $\mathrm{N}_{2}$ & -6.0 & 0.47 & 26.6 \\
$\mathrm{O}_{2}$ & -3.2 & 0.40 & 25.0 \\
Air & -2.0 & 0.48 & 23.5 \\
\hline
\end{tabular}

The results presented in Figure 2 and Table 1 indicate that the highest $\mu_{\mathrm{FE}}(26.6 \mathrm{~cm} / \mathrm{V} \cdot \mathrm{s})$ and lowest $V_{\mathrm{TH}}(=-6.0 \mathrm{~V})$ were achieved with the $\mathrm{N}_{2}$-annealed IGTO TFT. In contrast, the lowest $\mu_{\mathrm{FE}}$ $\left(=23.5 \mathrm{~cm}^{2} / \mathrm{V} \cdot \mathrm{s}\right)$ and highest $V_{\mathrm{TH}}(=-2.0 \mathrm{~V})$ were obtained with the air-annealed IGTO TFT. Finally, the corresponding values for the $\mathrm{O}_{2}$-annealed IGTO TFT were $\mu_{\mathrm{FE}}=25.0 \mathrm{~cm}^{2} / \mathrm{V} \cdot \mathrm{s}$ and $V_{\mathrm{TH}}=-3.2 \mathrm{~V}$, which lie between the corresponding values obtained for the $\mathrm{N}_{2}$ - and air-annealed IGTO TFTs. The $\mathrm{O}_{2}$-annealed IGTO TFT afforded the lowest $S S$ of $0.48 \mathrm{~V} / \mathrm{dec}$. as compared with those of the IGTO TFTs annealed in other environments. The obtained results clearly show that the post-deposition annealing atmosphere significantly affects the electrical performance of the IGTO TFTs.

Figure $3 \mathrm{a}-\mathrm{c}$ shows the time dependence of the transfer characteristics of the $\mathrm{N}_{2^{-}}, \mathrm{O}_{2^{-}}$, and air-annealed IGTO TFTs obtained under a constant overdrive voltage stress of $V_{\mathrm{OV}}=20 \mathrm{~V}$, where $V_{\mathrm{OV}}=V_{\mathrm{GS}}-V_{\mathrm{TH}}$. The insets in Figure $3 \mathrm{a}-\mathrm{c}$ show the shift of transfer characteristics on a magnified scale during the positive bias stress (PBS). Figure $3 \mathrm{~d}$ displays the $V_{\mathrm{TH}}$ shifts $\left(\Delta V_{\mathrm{TH}}\right)$ determined for the three IGTO TFTs at various stress times. Analysis of the transfer characteristics of the respective TFTs showed a shift of $V_{\mathrm{TH}}$ in the positive direction with an increase in the stress time, and the largest $\Delta V_{\mathrm{TH}}$ was observed for the air annealed IGTO TFT. However, the $\Delta V_{\mathrm{TH}}$ was significantly lower for the $\mathrm{N}_{2}$ - and $\mathrm{O}_{2}$-annealed IGTO TFTs than for the air-annealed IGTO TFT after subjection to PBS for the same duration. 

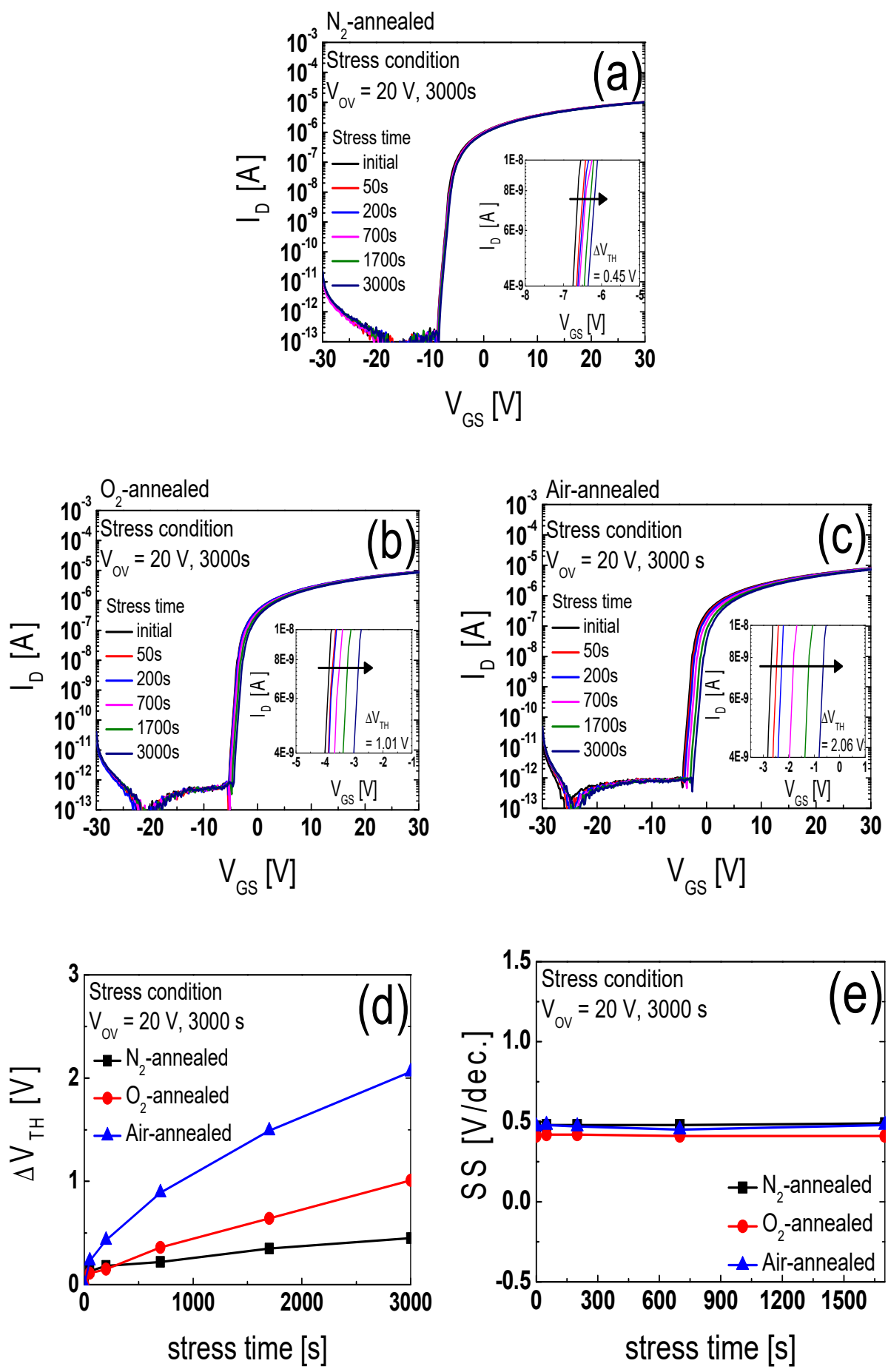

Figure 3. Time-dependence of transfer characteristics of (a) $\mathrm{N}_{2^{-}},(\mathbf{b}) \mathrm{O}_{2^{-}}$, and (c) air-annealed IGTO TFTs, determined under a constant overdrive voltage stress of $V_{\mathrm{OV}}=20 \mathrm{~V}$. The insets in (a-c) show the shift of transfer characteristics on a magnified scale. (d) $\Delta V_{\mathrm{TH}}$ values obtained for the $\mathrm{N}_{2^{-}}, \mathrm{O}_{2^{-}}$, and air-annealed IGTO TFTs after subjection to PBS various times. (e) Subthreshold swing (SS) values obtained for the $\mathrm{N}_{2^{-}}, \mathrm{O}_{2^{-}}$, and air-annealed IGTO TFTs at every PBS time.

Figure 3e displays the SS variation determined for the three IGTO TFTs at various stress times. The $S S$ value remains nearly unchanged during the PBS. Therefore, we did not consider additional defect generation in the active region during the PBS [25,26]. 
Figure 4a-e displays the time-dependence of the transfer characteristics, $\Delta V_{\text {th }}$, and $S S$ values of the $\mathrm{N}_{2^{-}}, \mathrm{O}_{2^{-}}$, and air-annealed IGTO TFTs obtained after the application of a constant bias stress $V_{\mathrm{OV}}=-15 \mathrm{~V}$ under illumination by a light-emitting diode (LED) backplane unit with a brightness of $3000 \mathrm{~lx}$.
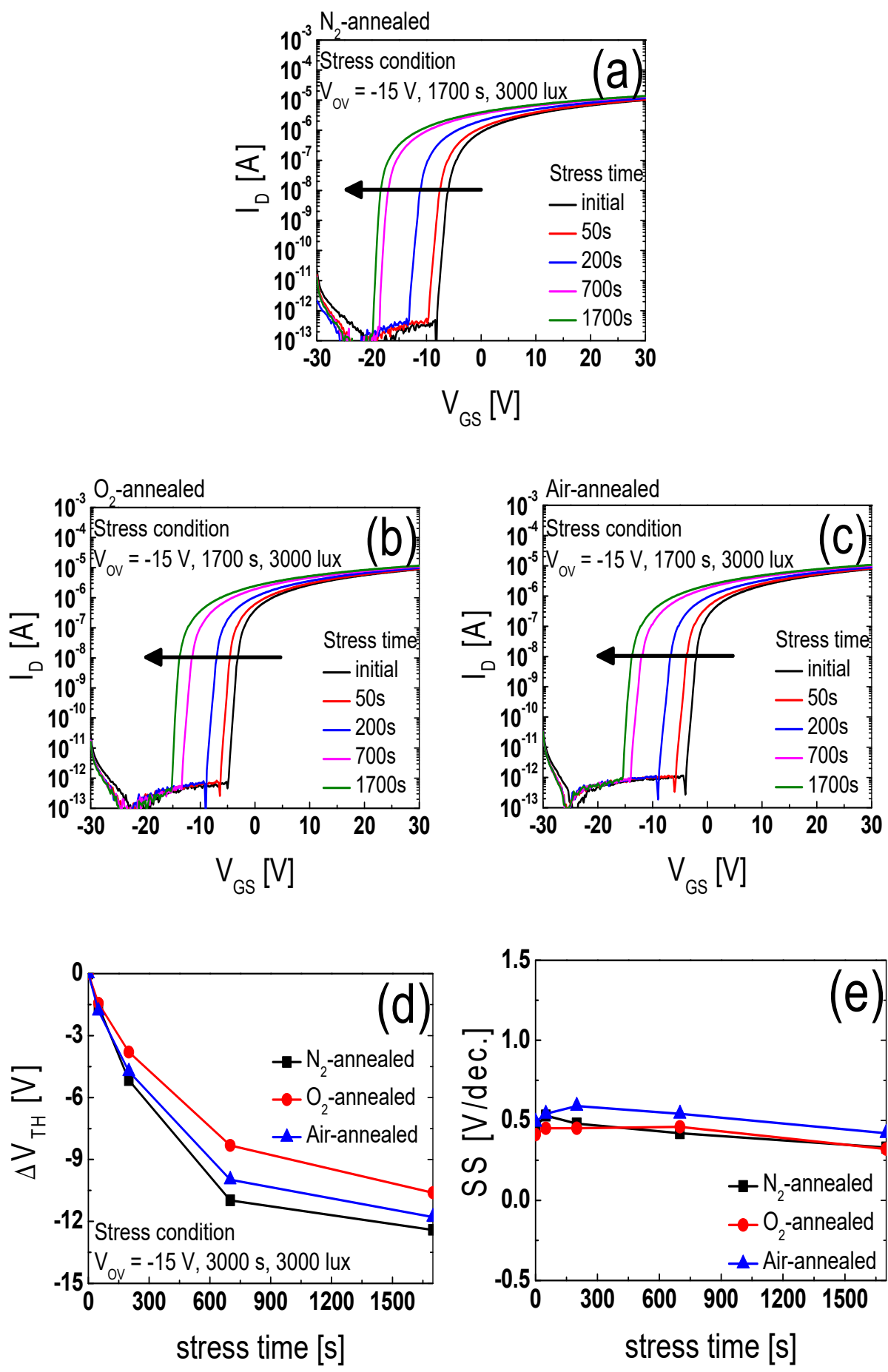

Figure 4. Time-dependence of transfer characteristics of (a) $\mathrm{N}_{2^{-}},(\mathbf{b}) \mathrm{O}_{2^{-}}$, and (c) air-annealed IGTO TFTs after the application of a constant bias stress $V_{\mathrm{OV}}=-15 \mathrm{~V}$ under illumination by a LED backplane unit with a brightness of $3000 \mathrm{~lx}$. (d) $\Delta V_{\text {TH }}$ values obtained for the $\mathrm{N}_{2}, \mathrm{O}_{2}$, and air annealed IGTO TFTs after subjection to negative bias illumination stress (NBIS) various times. (e) The SS values obtained for the $\mathrm{N}_{2^{-}}, \mathrm{O}_{2^{-}}$, and air annealed IGTO TFTs at every NBIS time. 
The transfer curves of all IGTO TFTs shifted in the negative direction with an increase in the stress time. The largest $V_{\mathrm{TH}}$ shift was observed for the $\mathrm{N}_{2}$-annealed IGTO TFT; however, for the $\mathrm{O}_{2}$ - and air annealed IGTO TFTs, $\Delta V_{\text {TH }}$ was lower than that of the $\mathrm{N}_{2}$-annealed IGTO TFT after subjection to the negative bias illumination stress (NBIS). The $S S$ value remained nearly unchanged during the NBIS.

Figures 3 and 4 demonstrate that the post-deposition annealing environment affectrf not only the electrical properties of the IGTO TFTs, but also their stability under PBS and NBIS [27-29]. To elucidate the physical mechanism responsible for the processes illustrated in Figures 3 and 4, the IGTO thin films annealed under different atmospheres were characterized by XRD, UV-vis-NIR spectroscopy, and XPS.

Figure 5 shows the XRD patterns of the $\mathrm{N}_{2^{-}}, \mathrm{O}_{2^{-}}$, and air annealed $20 \mathrm{~nm}$ thick IGTO thin films deposited on glass substrates. The obtained diffraction patterns contained only halo peaks at approximately $23^{\circ}$ and $45^{\circ}$, originating from the glass substrates [30]; this suggests that the IGTO thin films comprised an amorphous phase, regardless of the annealing environment.

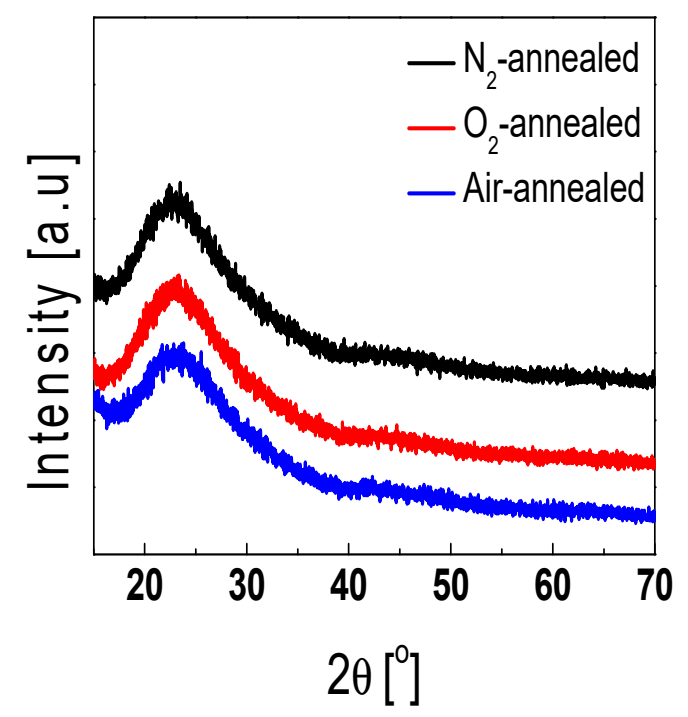

Figure 5. X-ray diffraction (XRD) patterns of $\mathrm{N}_{2^{-}}, \mathrm{O}_{2^{-}}$, and air annealed $20 \mathrm{~nm}$-thick IGTO thin films deposited on the glass substrates.

Figure 6a shows the optical transmittance spectra of the $\mathrm{N}_{2^{-}}, \mathrm{O}_{2^{-}}$, and air annealed $20 \mathrm{~nm}$-thick IGTO thin films on the glass substrates, which were recorded in the wavelength range of 300-1400 nm. The optical transmittance of the glass substrate was subtracted from the obtained spectra to determine the actual optical transmittance of the deposited IGTO thin films. Figure $6 \mathrm{~b}$ shows the Tauc plot constructed from the spectra presented in Figure 6a. The optical bandgap $\left(E_{\mathrm{g}}\right)$ of the IGTO thin films was approximately $3.88 \mathrm{eV}$ regardless of the annealing environment, which indicates that the annealing environment had no effect on the $E_{\mathrm{g}}$ value.

Figure $7 \mathrm{a}-\mathrm{c}$ displays the XPS O 1 s spectra of the $\mathrm{N}_{2^{-}}, \mathrm{O}_{2^{-}}$, and air annealed IGTO thin films, respectively, recorded for the middle of the thin films. The obtained XPS profiles were deconvoluted into three sub-peaks originating from the lattice oxygen $\left(O_{\mathrm{I}}\right), V_{\mathrm{O}}\left(\mathrm{O}_{\mathrm{II}}\right)$, and impurity-related oxygen $\left(O_{\text {III }}\right)$, respectively, using the Gaussian function. The binding energies of these components were fixed at $529.8 \pm 0.1 \mathrm{eV}, 530.7 \pm 0.1 \mathrm{eV}$, and $531.8 \pm 0.1 \mathrm{eV}$, respectively [7,31]. Figure $7 \mathrm{~d}$ shows the relative areas of the $O_{\mathrm{I}}, O_{\mathrm{II}}$, and $O_{\mathrm{III}}$ peaks, which were obtained for the IGTO thin films, annealed under different atmospheres. The XPS data presented in Figure 7 indicate that the relative area of the $O_{\text {III }}$ component of the air-annealed IGTO thin film was much larger than that of the $\mathrm{N}_{2}$ - and $\mathrm{O}_{2}$-annealed films. In previous studies on oxide thin films and TFTs, $O_{\text {III }}$ was primarily attributed to the oxygen bonds in $\mathrm{OH}$ functional groups, which generate acceptor-like states near the conduction band (CB) edge and enhance electron trapping during PBS application because of their polar nature in oxide 
semiconductors, such as IGZO and IGTO [32-35]. Therefore, the small value of $\mu_{\mathrm{FE}}$, large value of $S S$, and poor PBS stability of the air-annealed IGTO TFT can be attributed to the high concentration of $\mathrm{OH}$ groups within the channel layer that originated from the $\mathrm{H}_{2} \mathrm{O}$ species present in air. Because an n-type TFT with a higher density of acceptor-like states near the CB edge requires a larger $V_{\mathrm{GS}}$ to switch on and fill up the states, the highest $V_{\mathrm{TH}}$ value obtained for the air-annealed IGTO TFT can also be ascribed to the large number of $\mathrm{OH}$ groups within the IGTO channel.
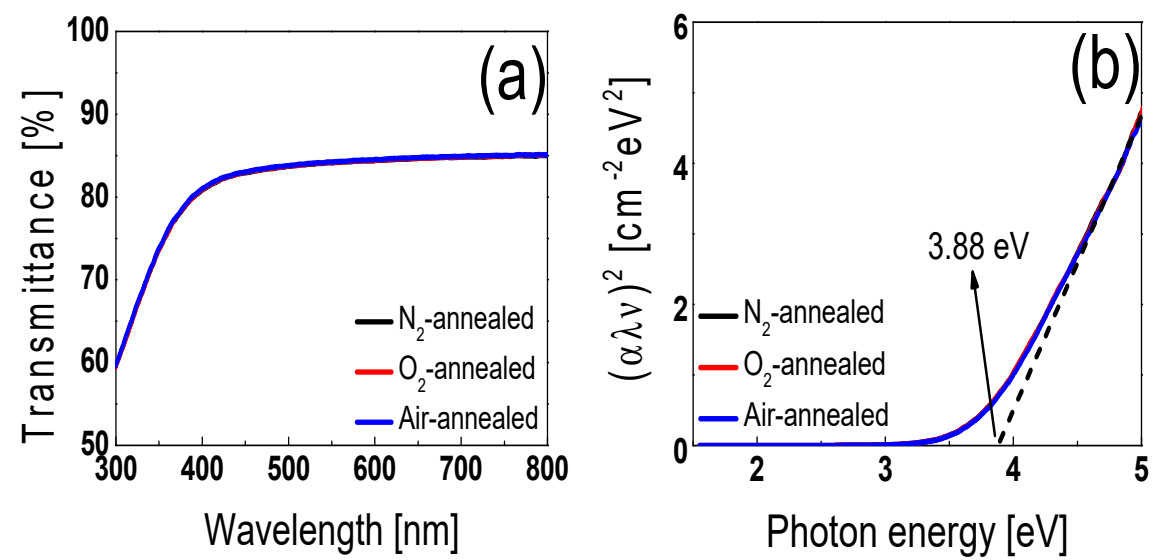

Figure 6. (a) Optical transmittance spectra recorded for $\mathrm{N}_{2^{-}}, \mathrm{O}_{2^{-}}$, and ai -annealed $20 \mathrm{~nm}$-thick IGTO thin films. (b) Tauc plot constructed from the optical transmittance spectra.
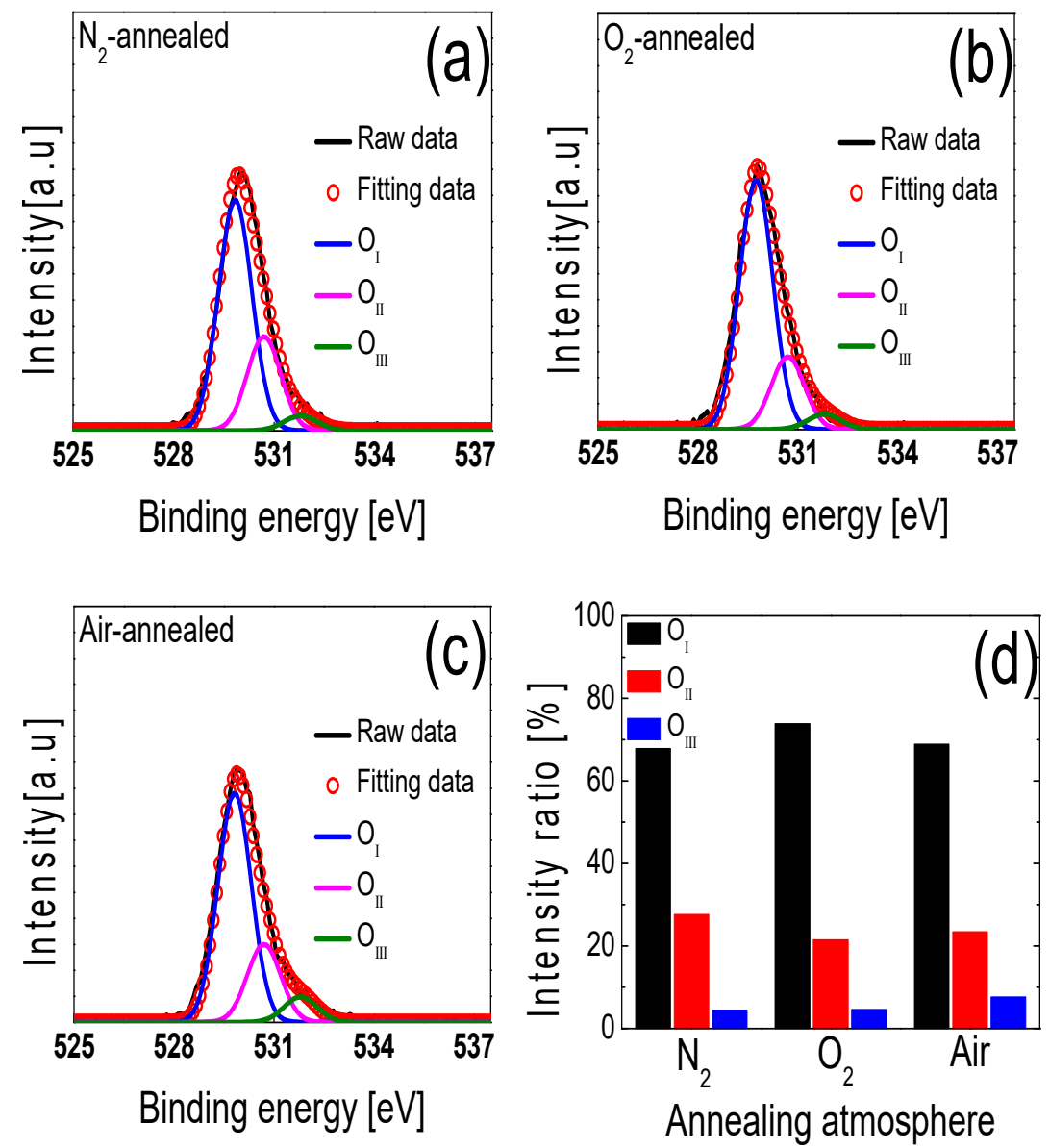

Figure 7. X-ray photoelectron spectroscopy (XPS) O 1 s spectra of (a) $\mathrm{N}_{2^{-}}$, (b) $\mathrm{O}_{2^{-}}$, and (c) air annealed IGTO thin films, respectively, recorded for the middle of the thin films. (d) Relative areas of the $O_{\mathrm{I}}, \mathrm{O}_{\mathrm{II}}$, and $O_{\text {III }}$ peak regions that were obtained for the IGTO thin films annealed under different atmospheres. 
Further, the largest $O_{\text {II }}$ relative area was obtained for the $\mathrm{N}_{2}$-annealed IGTO thin film (Figure 7). Note that $V_{\mathrm{O}}$ generates shallow and deep donor states within the oxide channel layer. The shallow donor states supply electrons to the $\mathrm{CB}$; thus, the electron concentration increases with an increase in the number of $V_{\mathrm{O}}$ sites within the channel layer. Furthermore, the higher electron concentration promotes the formation of percolation conduction paths in oxide semiconductors, such as IGZO and IGTO, making it very difficult to turn off the transistor [36-38]. Therefore, the low value of $V_{\mathrm{TH}}$ and the high values of $\mu_{\mathrm{FE}}$ and SS obtained for the $\mathrm{N}_{2}$-annealed IGTO TFT can be attributed to the large $V_{\mathrm{O}}$ concentration within the channel layer caused by the desorption of oxygen atoms during $\mathrm{N}_{2}$ annealing. The poor NBIS stability of the $\mathrm{N}_{2}$-annealed IGTO TFT is likely caused by the high density of $V_{\mathrm{O}}$ within the IGTO channel, because $V_{\mathrm{O}}$ generates $V_{\mathrm{O}}{ }^{2+}$ species, which subsequently diffuse toward the gate insulator/channel interface under NBIS [39].

\section{Conclusions}

The effects of various post-deposition annealing environments on the electrical characteristics and stability of high-mobility IGTO TFTs were evaluated herein. The post-deposition annealing process was conducted at $180{ }^{\circ} \mathrm{C}$ under $\mathrm{N}_{2}, \mathrm{O}_{2}$, or air atmosphere. The lowest $\mu_{\mathrm{FE}}$ and highest $S S$ and $V_{\mathrm{TH}}$ were obtained with the air annealed IGTO TFT, along with the lowest PBS stability. This phenomenon is attributed primarily to the large number of $\mathrm{OH}$ groups within the IGTO channel layer that originated from the $\mathrm{H}_{2} \mathrm{O}$ molecules in air. The $\mu_{\mathrm{FE}}$ and PBS stability of the $\mathrm{N}_{2}$ - and $\mathrm{O}_{2}$-annealed IGTO TFTs are higher than those of the air-annealed IGTO TFT. However, the NBIS stability of the $\mathrm{N}_{2}$-annealed IGTO TFTs is lower, accompanied by a larger negative shift of the $V_{\mathrm{TH}}$ values compared with the corresponding parameters for the $\mathrm{O}_{2}$-annealed IGTO TFTs because of the large $V_{\mathrm{O}}$ concentration within the channel layer, caused by the desorption of oxygen atoms during $\mathrm{N}_{2}$ annealing. The obtained results suggest that $\mathrm{O}_{2}$ gas is the most suitable annealing environment for optimizing the electrical properties and stability of IGTO TFTs.

Author Contributions: Conceptualization, H.-S.J. and H.-I.K.; experiment, H.-S.J., H.S.C., and S.H.H.; data analysis, H.-S.J. and H.-I.K., writing-original draft preparation, H.-S.J.; supervision, H.-I.K.; writing-review and editing, H.-I.K. All authors have read and agreed to the published version of the manuscript.

Funding: This research was supported by the National Research Foundation of Korea (NRF), funded by the Korean Government (MSIT) (grant No. 2020R1A2B5B01001765). The authors thank Shinhyuk Kang (Samsung Corning Advanced Glass) for providing the IGTO sputter target used in this work.

Conflicts of Interest: The authors declare no conflict of interest.

\section{References}

1. Nomura, K.; Ohta, H.; Takagi, A.; Kamiya, T.; Hirano, M.; Hosono, H. Room-temperature fabrication of transparent flexible thin-film transistors using amorphous oxide semiconductors. Nature 2004, 432, 488-492. [CrossRef] [PubMed]

2. Yabuta, H.; Sano, M.; Abe, K.; Aiba, T.; Den, T.; Kumomi, H.; Nomura, K.; Kamiya, T.; Hosono, H. High mobility thin-film transistor with amorphous $\mathrm{InGaZnO}_{4}$ channel fabricated by room temperature rf magnetron sputtering. Appl. Phys. Lett. 2006, 89, 112123. [CrossRef]

3. Suresh, A.; Muth, J.F. Bias stress stability of indium gallium zinc oxide channel based transparent thin film transistors. Appl. Phys. Lett. 2008, 92, 033502. [CrossRef]

4. Kamiya, T.; Nomura, K.; Hosono, H. Present status of amorphous In-Ga-Zn-O thin-film transistors. Sci. Technol. Adv. Mater. 2010, 11, 044305. [CrossRef] [PubMed]

5. Park, M.-J.; Yun, D.-J.; Ryu, M.-K.; Yang, J.-H.; Pi, J.-E.; Kwon, O.-S.; Kim, G.H.; Hwang, C.-S.; Bak, J.-Y.; Yoon, S.-M. Improvements in the bending performance and bias stability of flexible InGaZnO thin film transistors and optimum barrier structures for plastic poly (ethylene naphthalate) substrates. J. Mater. Chem. C 2015, 3, 4779-4786. [CrossRef] 
6. Jeong, H.-J.; Lee, H.-M.; Oh, K.-T.; Park, J.; Park, J.-S. Enhancement of In-Sn-Ga-O TFT performance by the synergistic combination of $\mathrm{UV}+\mathrm{O}_{3}$ radiation and low temperature annealing. J. Electroceram. 2016, 37, 158-162. [CrossRef]

7. Oh, C.; Jang, H.; Kim, H.W.; Jung, H.; Park, H.; Cho, J.; Kim, B.S. Influence of oxygen partial pressure in In-Sn-Ga-O thin-film transistors at a low temperature. J. Alloy. Compd. 2019, 805, 211-217. [CrossRef]

8. Kim, H.-A.; Kim, J.O.; Hur, J.S.; Son, K.-S.; Lim, J.H.; Cho, J.; Jeong, J.K. Achieving High Mobility in IGTO Thin-Film Transistors at a Low Temperature via Film Densification. IEEE Trans. Electron Devices 2018, 65, 4854-4860. [CrossRef]

9. Jin, J.; Luo, Y.; Bao, P.; Brox-Nilsen, C.; Potter, R.; Song, A. Tuning the electrical properties of ZnO thin-film transistors by thermal annealing in different gases. Thin Solid Films 2014, 552, 192-195. [CrossRef]

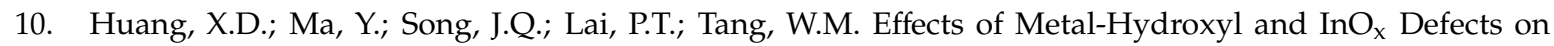
Performance of InGaZnO Thin-Film Transistor. IEEE Trans. Electron Devices 2018, 64, 1009-1013. [CrossRef]

11. Kim, H.J.; Han, C.J.; Yoo, B.; Lee, J.; Lee, K.; Lee, K.H.; Oh, M.S. Effects of Intense Pulsed Light (IPL) Rapid Annealing and Back-Channel Passivation on Solution-Processed In-Ga-Zn-O Thin Film Transistors Array. Micromachines 2020, 11, 508. [CrossRef] [PubMed]

12. Choi, S.; Kim, J.Y.; Kang, H.; Ko, D.; Rhee, J.; Choi, S.J.; Kim, D.M.; Kim, D.H. Effect of oxygen content on current stress-induced instability in bottom-gate amorphous InGaZnO thin-film transistors. Materials 2019, 12, 3149. [CrossRef]

13. Huang, X.; Zhou, D.; $\mathrm{Xu}, \mathrm{W}$. Influence of $\mathrm{N}_{2} / \mathrm{O}_{2}$ Partial Pressure Ratio during Channel Layer Deposition on the Temperature and Light Stability of a-InGaZnO TFTs. Appl. Sci. 2019, 9, 1880. [CrossRef]

14. Wang, D.; Furuta, M.; Tomai, S.; Yano, K. Understanding the Role of Temperature and Drain Current Stress in InSnZnO TFTs with Various Active Layer Thicknesses. Nanomaterials 2020, 10, 617. [CrossRef]

15. Hu, S.; Ning, H.; Lu, K.; Fang, Z.; Li, Y.; Yao, R.; Xu, M.; Wang, L.; Peng, J.; Lu, X. Mobility Enhancement in Amorphous In-Ga-Zn-O Thin-Film Transistor by Induced Metallic in Nanoparticles and Cu Electrodes. Nanomaterials 2018, 8, 197. [CrossRef]

16. Wang, D.; Furuta, M.; Tomai, S.; Yano, K. Impact of Photo-Excitation on Leakage Current and Negative Bias Instability in InSnZnO Thickness-Varied Thin-Film Transistors. Nanomaterials 2020, 10, 1782. [CrossRef] [PubMed]

17. Park, J.; Kim, D.-K.; Park, J.-I.; Kang, I.M.; Jang, J.; Kim, H.; Lang, P.; Bae, J.-H. Numerical Analysis on Effective Mass and Traps Density Dependence of Electrical Characteristics of a-IGZO Thin-Film Transistors. Electronics 2020, 9, 119. [CrossRef]

18. Zhou, X.; Han, D.; Dong, J.; Li, H.; Yi, Z.; Zhang, X.; Wang, Y. The Effects of Post Annealing Process on the Electrical Performance and Stability of Al-Zn-O Thin-Film Transistors. IEEE Electron Device Lett. 2020, 41, 569-572. [CrossRef]

19. Kikuchi, Y.; Nomura, K.; Yanagi, H.; Kamiya, T.; Hirano, M.; Hosono, H. Device characteristics improvement of a-In-Ga-Zn-O TFTs by low-temperature annealing. Thin Solid Films 2010, 518, 3017-3021. [CrossRef]

20. Fuh, C.S.; Sze, S.M.; Liu, P.T.; Teng, L.F.; Chou, Y.T. Role of environmental and annealing conditions on the passivation-free in-Ga-Zn-O TFT. Thin Solid Films 2011, 520, 1489-1494. [CrossRef]

21. Qu, M.; Chang, C.-H.; Meng, T.; Zhang, Q.; Liu, P.-T.; Shieh, H.-P.D. Stability study of indium tungsten oxide thin-film transistors annealed under various ambient conditions. Phys. Status Solidi A 2017, 214, 1600465. [CrossRef]

22. Chung, W.-F.; Chang, T.-C.; Li, H.-W.; Tseng, T.-Y.; Tai, Y.-H. Effects of Post-Deposition Annealing Atmosphere and Duration on Sol-Gel Derived Amorphous Indium-Zinc-Oxide Thin Film Transistors. ECS Trans. 2011, 41, 265-271. [CrossRef]

23. Su, J.; Yang, H.; Ma, Y.; Li, R.; Jia, L.; Liu, D.; Zhang, X. Annealing atmosphere-dependent electrical characteristics and bias stability of N-doped InZnSnO thin film transistors. Mater. Sci. Semicond. Process. 2020, 113, 105040. [CrossRef]

24. Lee, H.; Ha, S.H.; Bae, J.H.; Kang, I.M.; Kim, K.; Lee, W.Y.; Jang, J. Effect of annealing ambient on $\mathrm{SnO}_{2}$ thin film transistors via an ethanol-based sol-gel route. Electronics 2019, 8, 995. [CrossRef]

25. Zhou, X.; Shao, Y.; Zhang, L.; Lu, H.; He, H.; Han, D.; Wang, Y.; Zhang, S. Oxygen Interstitial Creation in a-IGZO Thin-Film Transistors Under Positive Gate-Bias Stress. IEEE Electron Device Lett. 2017, 38, 1252-1255. [CrossRef] 
26. Kim, D.H.; Choi, S.; Jang, J.; Kang, H.; Kim, D.M.; Choi, S.-J.; Kim, Y.-S.; Oh, S.; Baeck, J.H.; Bae, J.U.; et al. Experimental decomposition of the positive bias temperature stress-induced instability in self-aligned coplanar InGaZnO thin-film transistors and its modeling based on the multiple stretched-exponential function. J. Soc. Inf. Disp. 2017, 25, 98-107. [CrossRef]

27. Kim, Y.K.; Ahn, C.H.; Yun, M.G.; Cho, S.W.; Kang, W.J.; Cho, H.K. Periodically pulsed wet annealing approach for low-temperature processable amorphous InGaZnO thin film transistors with high electrical performance and ultrathin thickness. Sci. Rep. 2016, 6, 26287. [CrossRef]

28. Chowdhury, M.D.H.; Um, J.G.; Jang, J. Remarkable changes in interface O vacancy and metal-oxide bonds in amorphous indium-gallium-zinc-oxide thin-film transistors by long time annealing at $250{ }^{\circ} \mathrm{C}$. Appl. Phys. Lett. 2014, 105, 233504. [CrossRef]

29. Kim, H.-D.; An, H.-M.; Seo, Y.; Zhang, Y.; Park, J.S.; Kim, T.G. Hydrogen passivation effects under negative bias temperature instability stress in metal/silicon-oxide/silicon-nitride/silicon-oxide/silicon capacitors for flash memories. Microelectron. Reliab. 2010, 50, 21-25. [CrossRef]

30. Jung, S.H.; Moon, H.J.; Ryu, M.K.; Cho, K.I.; Bae, B.S.; Yun, E.-J. The effects of high-energy electron beam irradiation on the properties of IGZO thin films prepared by rf magnetron sputtering. J. Ceram. Process. Res. 2012, 13, s246-s250. [CrossRef]

31. Jeong, H.-J.; Ok, K.-C.; Park, J.; Lim, J.; Cho, J.; Park, J.-S. Stability Improvement of In-Sn-Ga-O Thin-Film Transistors at Low Annealing Temperatures. IEEE Electron Device Lett. 2015, 36, 1160-1162. [CrossRef]

32. Lee, E.; Kim, T.H.; Lee, S.W.; Kim, J.H.; Kim, J.; Jeong, T.G.; Ahn, J.-H.; Cho, B. Improved Electrical Performance of a Sol-Gel IGZO Transistor with High-k $\mathrm{Al}_{2} \mathrm{O}_{3}$ Gate Dielectric Achieved by Post Annealing. Nano Converg. 2019, 6, 1-8. [CrossRef]

33. Ji, H.; Hwang, A.Y.; Lee, C.K.; Yun, P.S.; Bae, J.U.; Park, K.-S.; Jeong, J.K. Improvement in Field-Effect Mobility of Indium Zinc Oxide Transistor by Titanium Metal Reaction Method. IEEE Trans. Electron Devices 2015, 62, 1009-1013. [CrossRef]

34. Kumaran, S.; Liu, M.-T.; Lee, K.-Y.; Tai, Y. The Impact of Solvents on the Performances of Solution-Processed Indium Gallium Zinc Oxide Thin-Film Transistors Using Nitrate Ligands. Adv. Eng. Mater. 2020, 22, 1901053. [CrossRef]

35. Kim, S.T.; Shin, Y.; Yun, P.S.; Bae, J.U.; Chung, I.J.; Jeong, J.K. Achieving High Carrier Mobility Exceeding $70 \mathrm{~cm}^{2} / \mathrm{Vs}$ in Amorphous Zinc Tin Oxide Thin-Film Transistors. Electron. Mater. Lett. 2017, 13, 406-411. [CrossRef]

36. Lee, S.; Ghaffarzadeh, K.; Nathan, A.; Robertson, J.; Jeon, S.; Kim, C.; Song, I.-H.; Chung, U.I. Trap-limited and percolation conduction mechanisms in amorphous oxide semiconductor thin film transistors. Appl. Phys. Lett. 2011, 98, 203508. [CrossRef]

37. Yoon, J.; Jung, H.; Jang, J.T.; Lee, J.; Lee, Y.; Lim, M.; Kim, D.M.; Kim, D.H.; Choi, S.J. Hybrid Complementary inverter based on carbon nanotube and IGZO thin-film transistors with controlled process conditions. J. Alloy. Compd. 2018, 762, 456-462. [CrossRef]

38. Mativenga, M.; Um, J.G.; Jang, J. Reduction of Bias and Light Instability of Mixed Oxide Thin-Film Transistors. Appl. Sci. 2017, 7, 885. [CrossRef]

39. Oh, H.; Yoon, S.M.; Ryu, M.K.; Hwang, C.S.; Yang, S.; Park, S.H. Photon-accelerated negative bias instability involving subgap states creation in amorphous In-Ga-Zn-O thin film transistor. Appl. Phys. Lett. 2010, 97, 183502. [CrossRef]

Publisher's Note: MDPI stays neutral with regard to jurisdictional claims in published maps and institutional affiliations.

(C) 2020 by the authors. Licensee MDPI, Basel, Switzerland. This article is an open access article distributed under the terms and conditions of the Creative Commons Attribution (CC BY) license (http://creativecommons.org/licenses/by/4.0/). 